IZA DP No. 5016

Social Preferences in Childhood and Adolescence: A Large-Scale Experiment

Matthias Sutter

Francesco Feri

Martin G. Kocher
Peter Martinsson

Katarina Nordblom

Daniela Rützler

June 2010 


\title{
Social Preferences in Childhood and Adolescence: A Large-Scale Experiment
}

\author{
Matthias Sutter \\ University of Innsbruck, University of Gothenburg and IZA \\ Francesco Feri \\ University of Innsbruck \\ Martin G. Kocher \\ University of East Anglia and University of Innsbruck \\ Peter Martinsson \\ University of Gothenburg \\ Katarina Nordblom \\ University of Gothenburg and Uppsala University \\ Daniela Rützler \\ University of Innsbruck
}
June 2010
IZA
P.O. Box 7240
53072 Bonn
Germany

Discussion Paper No. 5016

Phone: +49-228-3894-0

Fax: +49-228-3894-180

E-mail: iza@iza.org

Any opinions expressed here are those of the author(s) and not those of IZA. Research published in this series may include views on policy, but the institute itself takes no institutional policy positions.

The Institute for the Study of Labor (IZA) in Bonn is a local and virtual international research center and a place of communication between science, politics and business. IZA is an independent nonprofit organization supported by Deutsche Post Foundation. The center is associated with the University of Bonn and offers a stimulating research environment through its international network, workshops and conferences, data service, project support, research visits and doctoral program. IZA engages in (i) original and internationally competitive research in all fields of labor economics, (ii) development of policy concepts, and (iii) dissemination of research results and concepts to the interested public.

IZA Discussion Papers often represent preliminary work and are circulated to encourage discussion. Citation of such a paper should account for its provisional character. A revised version may be available directly from the author. 
IZA Discussion Paper No. 5016

June 2010

\section{ABSTRACT \\ Social Preferences in Childhood and Adolescence: A Large-Scale Experiment}

Social preferences have been shown to be an important determinant of economic decision making for many adults. We present a large-scale experiment with 883 children and adolescents, aged eight to seventeen years. Participants make decisions in eight simple, one-shot allocation tasks, allowing us to study the distribution of social preference types across age and across gender. Our results show that when children and teenagers grow older, inequality aversion becomes a gradually less prominent motivating force of allocation decisions. At the same time, efficiency concerns increase in importance for boys, and maximin-preferences turn more important in shaping decisions of girls.

JEL Classification: C91, D63, D64

Keywords: $\quad$ social preferences, children, age, gender, experiment

Corresponding author:

Matthias Sutter

Department of Public Finance

University of Innsbruck

Universitaetsstrasse 15

A-6020 Innsbruck

Austria

E-mail: matthias.sutter@uibk.ac.at

\footnotetext{
* We would like to thank Thomas Plankensteiner from the Central School Administration Board of Tyrol (Landesschulrat für Tirol) and the principals of the participating schools (Max Gnigler, Gottfried Heiss, Siegmund Heel, Ulrike Künstle, Hermann Lergetporer, Bernhard Schretter and Peter Paul Steinringer) for making this study possible. We have received many helpful comments from the audiences at the International Conference on The Economic Child in Milan, the International Meeting on Experimental and Behavioral Economics in Granada, the Spring Meeting of Young Economists in Istanbul, and the Meeting of the European Economic Association in Barcelona. Financial support from the University of Innsbruck and the Austrian Central Bank (Jubilaeumsfonds Projekt 12588), the Swedish Research Council (Vetenskapsrådet), and the Jan Wallander and Tom Hedelius Foundation is gratefully acknowledged.
} 


\section{Introduction}

Social or other-regarding preferences have been shown to play an important role in many areas of human decision making. For instance, when contracts are incomplete, social preferences such as inequality aversion or norms like reciprocity have a positive impact on the relationship between employers and employees and on the economic efficiency of interaction on labor markets (Fehr, Kirchsteiger and Riedl, 1993; Fehr and Gächter, 2000; Charness and Dufwenberg, 2006). Caring also for others and not only for oneself is obviously a major driving force behind various forms of charitable giving (Harbaugh, 1998; Vesterlund, 2003). Bilateral or small-group bargaining is another example for the importance of social preferences, since different variants - such as inequality aversion (Fehr and Schmidt, 1999; Bolton and Ockenfels, 2000), social welfare considerations of overall efficiency or the intention to maximize the welfare of the worst-off party in the reference group (Charness and Rabin, 2002) - shape the economic outcome of the bargaining process.

While the impact of social preferences on economic behavior has been analyzed extensively and by now is quite well understood for adults (Camerer, 2003), much less is known for children and adolescents. Studying potential changes of social preferences when children and teenagers grow up is interesting because it reveals insights into how social orientations originate, how they evolve with age and how they interact with relevant socioeconomic and background variables such as gender or the number of siblings. However, knowing more on the economic behavior of children and adolescents is also relevant in itself because they have become more and more important as economic decision makers and consumers in their households (McNeal, 1992; Dauphin et al., 2010). Finally, identifying potential changes in social preferences when humans grow up provides an indication on possible interventions in education that might help to prevent conflict in interactions of people (children) of different age or of different gender.

In this paper, we present a large-scale experiment with 883 children and adolescents, aged eight to seventeen years. Using eight simple, one-shot allocation tasks (taken from Engelmann and Strobel, 2004), we study the distribution of social preference types across age and gender and their interaction with background variables. The eight tasks were designed by Engelmann and Strobel (2004) to explicitly test and discriminate between selfishness, maximin-preferences, efficiency-loving preferences, and two prominent theories of inequality 
aversion by Fehr and Schmidt (1999, henceforth F\&S) and Bolton and Ockenfels (2000, henceforth ERC). According to the choices made in the incentivized allocation decisions, we can classify our experimental subjects into the different social preference types. The classification is done by conducting a maximum likelihood error-rate analysis of subjects' decisions (following, in general, the econometric model used in Costa-Gomes, Crawford and Broseta, 2001). The mixture model used here assumes that each subject's type is drawn from a common prior distribution over five types (Selfishness, Efficiency, Maximin, F\&S, ERC) and that a subject's type is the same for all eight decisions, but that decision makers are allowed to make errors.

Our results show that roughly $20 \%$ of decision makers in our experiment behave selfishly, and this fraction does neither depend on age nor on gender. In contrast to the apparent stability of the number of selfish types across age and gender, social preferences follow a clear pattern. While efficiency concerns are increasing with age in our male sample (from about $30 \%$ at the age of eight to roughly 50\% at the age of seventeen) and stay constant around $20 \%$ for females, the pattern is reversed for maximin-preferences. The latter become more important for females when they grow up, but stay rather constant for boys. Pure inequality aversion plays a role for a non-negligible fraction of decision maker in our younger age groups, where $\mathrm{F} \& \mathrm{~S}$ comes out as the empirically more suitable model to explain choices than ERC. In general, pure inequality aversion becomes less important as our subjects grow older.

In recent years, social preferences of children and adolescents have attracted growing interest of scholars in economics. Fehr, Bernhard and Rockenbach (2008) present a study with 229 children aged three to eight years. They show that egalitarianism, i.e., inequality aversion develops strongly over these age categories. Children at the age of three and four behave selfishly to a very large degree, whereas the majority of children aged seven or eight prefer egalitarian allocations that avoid both advantageous and disadvantageous inequality. More precisely, about $60 \%$ of seven- to eight-year old children can be classified as having egalitarian preferences, while the corresponding share for three- to four-year olds is only $20 \%$. The findings of Fehr et al. (2008) are largely in line with several other papers that have found older children to have stronger preferences for egalitarian distributions than younger children. Gummerum et al. (2010) find in a dictator game with 77 children aged three to five years that older children share more than younger children, and they show that girls are more generous 
than boys. Benenson, Pascoe and Radmore (2007) use a dictator game with 360 children aged four to nine years to demonstrate that older children and those from families with a higher socio-economic status behave more altruistically, i.e., prefer more egalitarian choices over more selfish ones. Harbaugh, Krause and Liday (2003) report an experiment with 310 children and teenagers aged seven to eighteen years, showing that young children offer considerably less to recipients in the dictator game and the ultimatum game than older children and adults. They also show that boys make smaller dictator proposals than girls, meaning that boys are, on average, more selfish. Almås et al. (2010) run experiments with 486 children from ten to eighteen years. They let them play modified dictator games and find that children's fairness norms evolve from favoring equality to favoring equity when they grow older. In one of their treatments, they vary the efficiency of the transfer and observe significantly stronger efficiency concerns in adolescents than in younger children. In line with our findings, they also report a gender effect, i.e. that male adolescents are stronger oriented towards efficiency than female adolescents.

Compared to the existing studies in economics our paper is different in at least three dimensions. First, by using the design of Engelmann and Strobel (2004) we are not only able to distinguish between selfish and non-selfish preferences. Our experiment allows distinguishing between five different social preference types (Selfishness, Efficiency, Maximin, F\&S, ERC). Second, using a mixture model, we can econometrically estimate for each single subject the probability to behave according to a specific social preference type. Hence, we are able to exploit our data beyond a mere description of choice frequencies and we can estimate the influence of age, gender, and other socio-demographic variables on the likelihood to observe a particular type. Third, our subject pool (with more than 800 participants) is much larger than the largest pool used in the previous studies mentioned above, thus clearly increasing the validity of the results.

The rest of the paper is organized as follows. In Section 2 we introduce the theoretical framework and explain our experimental design. In Section 3 we present the experimental results, first on an aggregate level and then on the basis of a mixture model that allows assessing the distribution of social preference types across age groups and gender. Section 4 concludes the paper. 


\section{The experiment}

\subsection{Theoretical framework}

We define the five types of decision makers regarding their social preferences following standard conventions in economics. Let $x_{i}$ and $x_{j}$ be the material payoffs of players $i$ and $j$. A player $i$ that maximizes $x_{i}$ regardless of $x_{j}$ in an allocation decision is said to be selfish (and the category is denoted Selfishness in the following).

Social welfare considerations can take on two specific forms. If subjects maximize $\sum_{k=i}^{j} x_{k}$ they are classified as Efficiency-types (following Utilitarian preferences), and if subject $i$ maximizes the $\min \left\{x_{i}, x_{j}\right\}$ with $x_{i} \geq x_{j}$ they are assigned to the class of Maximintype (following Rawlsian preferences). Both forms of social welfare considerations (Efficiency and Maximin) play an important role in the well-known behavioral model of Charness and Rabin (2002).

Inequality aversion has been captured in two seminal models. While in the model of Fehr and Schmidt (1999) inequality is measured as the difference of the own payoff to the other players' payoffs, and subjects have a disutility both from advantageous and disadvantageous inequality, the so-called ERC-model of Bolton and Ockenfels (2000) defines inequality merely as the deviation of a subject's payoff from the average payoff in her group.

More precisely, the utility function of player $i$ in the model of Fehr and Schmidt (1999) is specified as

$$
U_{i}(x)=x_{i}-\alpha_{i} \frac{1}{n-1} \sum_{j \neq i} \max \left\{x_{j}-x_{i}, 0\right\}-\beta_{i} \frac{1}{n-1} \sum_{j \neq i} \max \left\{x_{i}-x_{j}, 0\right\},
$$

where $n$ is the number of players, and it is assumed that the inequality sensitivity parameters satisfy two assumptions: (i) $\beta_{i} \leq \alpha_{i}$ and (ii) $0 \leq \beta_{i}<1$. A subject with preferences according to equation (1), given that $\alpha_{i}, \beta_{i}>0$, will be assigned to the $F \& S$-type in our data analysis.

In the model of Bolton and Ockenfels (2000) player $i$ maximizes her motivation function, which is given by

$$
v_{i}=v_{i}\left(y_{i}, \sigma_{i}\right),
$$

where $y_{i}$ denotes the player's own payoff and $\sigma_{i}$ player $i$ 's share of the total payoff in her group. For any given $y_{i}$ the value of the motivation function is maximized if 
$\sigma_{i}=y_{i} / c=1 / n$, where $c>0$ is the amount of money to be distributed. A subject with preferences according to (2) will be classified as an ERC-type in the following.

\subsection{Experimental design}

The design of Engelmann and Strobel (2004) was developed to discriminate between Selfishness, Efficiency, Maximin, and inequality aversion of the F\&S- and the ERC-type. In our experiment, each subject had to choose one out of three different allocations in eight different games. ${ }^{1}$ Each allocation assigns each of three persons (labeled persons 1 to 3) a specific amount of money (see Tables 1 to 3 below). Decisions were always made in the role of person 2 who had to choose an allocation that distributed money to persons 1,2 and 3 . Only at the end the experiment roles were finally determined by grouping three subjects together and randomly assigning them roles of person 1, 2 or 3, respectively. Then one randomly chosen game was implemented by paying the distribution that had been chosen by the subject in the role of person $2 .^{2}$ The eight games can be classified into three different sets of games that are introduced in the following.

\subsubsection{Taxation games}

In this set of games, the income of the decision maker (person 2) is the same in all three allocations and person 2 is always the "middle income” earner, while person 1 (person 3) is always the "high income" ("low income") earner. We selected two out of the four taxation games used in Engelmann and Strobel (2004). The payoffs of the two games are presented in Table 1 (games $\mathbf{F x}$ and $\mathbf{E x}$ according to the classification of Engelmann and Strobel, 2004). ${ }^{3}$

\section{Table 1 about here}

\footnotetext{
${ }^{1}$ Following the literature we call the experimental task of choosing one out of three allocations a "game", although there is no strategic interaction. Strictly speaking, the task is an individual decision making task on allocations of monetary payoffs.

${ }^{2}$ This procedure is an application of the strategy method. Note that Engelmann and Strobel (2004) also used the strategy method, but they also report that using the direct response method (where roles are determined right from the beginning, meaning that only participants in the role of person 2 had to make decisions) does not yield any differences in the distribution of social preferences.

${ }^{3}$ For derivations of the predictions summarized in Table 1, see Engelmann and Strobel (2004).
} 
The three allocations can be seen as involving different degrees of redistribution from person 1 to person 3. Obviously, one cannot identify selfish types with taxation games, since the payoff for person 2 is the same in all three allocations in both games. In both games Maximin and $F \& S$ predict the same choice, while ERC predicts a different allocation choice than F\&S. The efficient allocation (Efficiency) coincides in game Fx with F\&S and Maximin and in game Ex with $E R C$. As a consequence, it is possible to infer the relative importance of the two inequality models, $E R C$ and $F \& S$, without any confounding effects arising from efficiency concerns.

\subsubsection{Envy games}

In the three envy games presented in Table 2 (games $\mathbf{N}, \mathbf{N x}$ and $\mathbf{N y}$ according to the classification of Engelmann and Strobel, 2004) the decision maker (i.e., person 2) is again the "middle income" earner. The denotation "envy games" is derived from the fact that in these three games the decision maker can take money both from the "high income" person 1 and the "low income" person 3 at the same time. In game $\mathbf{N}$ the payoff of person 2 is fixed, and the $F \& S$-choice is Pareto-dominated by the $E R C$-compliant allocation, whereas the $E R C$-choice is also Pareto-dominated by the efficient/maximin choices. Games $\mathbf{N x}$ and $\mathbf{N y}$ are necessary to investigate whether selfishness dominates the non-selfish motives.

\section{Table 2 about here}

\subsubsection{Rich and Poor games}

Table 3 presents the third set of games, called "Rich and Poor" games. While the decision maker's payoffs are held constant in each game, the relation to the other two players' payoffs varies. In game $\mathbf{R}(\mathbf{P})$ the decision maker is the richest (poorest) group member in any allocation, while in game $\mathbf{E y}$ the decision maker is the "middle income" earner. In the "Rich and Poor" games F\&S and ERC predict the same choice of allocation. However, these games allow distinguishing between efficiency concerns, maximin preferences and inequality concerns. Like in the taxation games, the decision maker can reallocate money between person 1 and person 3, but now between the person with the "middle income" and the person with the "lowest income" (in game $\mathbf{R}$ ), respectively the person with the "highest income" (in game P). Game Ey is identical to game Ex except that the payoff of person 2 is $€ 3.6$ instead 
of $€$ 4.8. Note that this changes the ERC-prediction; it is now congruent with the allocation expected under F\&S- and under Maximin-preferences.

\section{Table 3 about here}

\subsection{Experimental procedure}

The experiment was run in three elementary schools and four high schools in the Federal State of Tyrol, Austria, from January to February 2008. It was part of a larger series of experiments in which we visited the involved schools repeatedly over a period of two years, asking children to make decisions in different experimental tasks (in order to study, among others, their risk and time preferences - see Sutter et al., 2010 - or their competitive behavior - see Sutter and Rützler, 2010). The project was approved by the central school administration board of Tyrol and the principals of the selected schools. All parents of involved children and teenagers were sent a letter with information on the project and its aim to study economic decision making, without revealing any specific details or experimental tasks to be completed. Parents could of course decide against letting their child participate, and five out of the more than 800 did so. All other parents consented. Children and teenagers were also instructed clearly that participation was completely voluntary. They were told that they could earn some money in the experiments, and no single child refused to participate in any of the experiments that we conducted.

The final number of participants was 883, aged eight to seventeen years. They were drawn from five different age groups, equivalent to school grades $3,5,7,9$, and 11 . Table 4 presents the number of participants by age and gender. ${ }^{4}$

\section{Table 4 about here}

The experiment, the incentive mechanism and the choices to be made were explained in great detail to the students in all 38 single classes, following a fixed script (see the Appendix for the script and for the decision sheet that we used). In order to check for the

\footnotetext{
${ }^{4}$ Note that one of the high schools involved is attended by girls only. Therefore, we have more girls than boys in our sample. There is no indication, however, that girls in single-sex schools exhibit a different behavior in our experiment than those in schools with co-education.
} 
comprehension of the rules we asked each participant to fill out a questionnaire that included two control questions prior to the start of the experiment. In total, $77 \%$ of our participants answered both questions correctly. The right-hand side of Table 4 shows the number of subjects with correct answers in each age group, indicating that the relative frequency of correct answers is strictly increasing in age. Our entire analysis is only based on those subjects who answered the questions correctly. This leaves us with 679 participants.

In order to provide roughly the same relative monetary incentives to all participants we varied the stake sizes with age. The amounts presented in Tables 1 to 3 are in Euros, and they applied for students aged fourteen to seventeen (grades 9 and 11). For the younger age groups (grades 3 to 7) these amounts were divided by two to account for their significantly lower pocket money and purchasing power. ${ }^{5}$ We presented the games a bit differently from the way used in Engelmann and Strobel (2004). For instance, we did not report the average payoffs of person 1 and 3 and the total payoff for each allocation on the decision sheet. This was done to keep the decision sheet as simple as possible.

The experiment was conducted as a pen-and-paper experiment, and it took approximately 40 minutes, including a post-experimental questionnaire on demographic characteristics. The students were informed at the beginning of the experiment that they would never be matched with someone from their own classes, but with someone from a parallel class of any of the schools participating in the experiment. As a consequence, the matching and calculation of payoffs were conducted afterwards. Monetary earnings were distributed in sealed envelopes marked with a student's ID within two weeks after the experiments had been conducted. ${ }^{6}$

\footnotetext{
${ }^{5}$ According to the survey we conducted with the same set of children, the average pocket money for $5^{\text {th }}$ graders is around $€ 5$ per week, while it is about $€ 13-14$ for $9^{\text {th }}$ graders.

${ }^{6}$ Since we were running several experiments with the children over the course of two years, children were sure (and had experienced it before) that we would come back and pay them the correct earnings according to the rules in the experiment.
} 


\section{Results}

\subsection{Overview of choices}

Tables 5 to 7 present an overview of the relative choice frequencies in the three different sets of games. We show overall averages (“Total sample”), separate average results for girls and boys, and also average results for each age group. In order to alleviate comparison of our results to choices made by adults we also include the relative choice frequencies from Engelmann and Strobel (2004) in the last line of each table.

\section{Tables 5 to 7 about here}

The general pattern emerging from Tables 5 to 7 is that we find noticeable differences between the choices of girls and boys in the Taxation games (Table 5) and the "Rich and Poor” games (Table 7). Age has also an influence on the choice frequencies in all three sets of games. In the following we present an econometric analysis of the influence of age and gender on social preferences.

\subsection{Econometric analysis of social preferences}

In the following, we conduct a maximum likelihood error-rate analysis of subjects' decisions following the general lines of the econometric model used in Costa-Gomes et al. (2001). The econometric model is a mixture model in which each subject's type is drawn from a common prior distribution over the five types considered in this paper: Selfishness, Efficiency, Maximin, F\&S, ERC. A subject's type is considered to be the same in all eight games, but decision makers are allowed to make errors.

More formally, let $i=1, \ldots, N$ index the subjects and let $k=1, \ldots, 5$ denote the different types of social preferences a subject can exhibit. Define $c=1$, 2, or 3 as the number of type-k's decisions in a given game. We assume that a type- $k$ subject normally makes a type $k$ decision, but in each game the subject makes an error with probability $\varepsilon_{k} \in[0,1]$. If a subject makes an error, she chooses each of the three available actions with probability $1 / 3$. For a type- $k$ subject, the probability of a single type $k$-decision is then $\frac{1}{c}-\frac{3-c}{3 c} \varepsilon_{k}$. Accordingly, the probability of any single non-type $k$ decision is $\varepsilon_{k} / 3$. We assume that the errors are i.i.d. across games and subjects. 
The likelihood function is constructed as follows. Let $T_{k, c}$ denote the total number of games in which there are $c$ type- $k$-decisions. Furthermore, $x_{k}^{i c}$ represents the number of subject $i$ 's decisions that equal type $k$ 's in games in which she has $c$ type-k-decisions and $x_{k}^{i}=\left(x_{k}^{i 1}, x_{k}^{i 2}, x_{k}^{i 3}\right), x^{i}=\left(x_{1}^{i}, \ldots, x_{5}^{i}\right)$, and $x=\left(x^{i}, \ldots, x^{N}\right)$. Let $p_{k}$ denote a subject's common prior

$k$-type probability, with $\sum_{k=1}^{5} p_{k}=1$ and $p=\left(p_{1}, \ldots, p_{5}\right)$, while $\varepsilon_{k}$ indicates the error rate of type $k$ and $\varepsilon=\left(\varepsilon_{1}, \ldots, \varepsilon_{5}\right)$. The probability of observing a particular sample with $x_{k}^{i}$ type- $k$ decisions when subject $i$ is of type $k$ can then be expressed as:

$$
L_{k}^{i}\left(\varepsilon_{k} \mid x_{k}^{i}\right)=\prod_{c=1,2,3}\left[\frac{1}{c}-\frac{3-c}{3 c} \varepsilon_{k}\right]^{x_{k}^{i c}}\left[\frac{\varepsilon_{k}}{3}\right]^{T_{k, c}-x_{k}^{i c}},
$$

Weighting the right-hand side by $p_{k}$, summing over $k$, taking logarithms, and summing over $i$ yields the log-likelihood function for the entire sample:

$$
\ln L(p, \varepsilon \mid x)=\sum_{i=1}^{n} \ln \sum_{k=1}^{5} p_{k} L_{k}^{i}\left(\varepsilon_{k} \mid x_{k}^{i}\right),
$$

With five types the model has nine independent parameters: four independent type probabilities $p_{k}$, and five type-error rates $\varepsilon_{k}$. We produce ten separate estimations of equation (4), separately for each age group and gender. The results on the distribution of social preference types using equation (4) are given in Table 8 and presented graphically in Figures 1 and 2.

\section{Table 8 and Figures 1 and 2 about here}

In general, we find that Efficiency and Maximin explain the largest fraction of subjects' social preferences. However, we observe clear effects of age and gender, and an interaction of both. From Figures 1 and 2 as well as Table 8 it is obvious that $F \& S$ preferences become less prominent with age. More precisely, the estimated probability of $F \& S$-preferences becomes even insignificant in the two oldest age groups. ERC-preferences are not significant in any of our age groups. Efficiency- and Maximin-types display an evolution with age that is gender-specific. For boys Efficiency becomes much more important with age, whereas the fraction of Efficiency-types for girls remains more or less constant. The reverse is observed for Maximin-preferences. Here we find a strong increase of the numbers 
classified as Maximin for girls, while (except for the youngest age group) the fraction is stable for boys. Efficiency concerns are significant for all age groups, for both boys and girls, and Maximin concerns are significant in all age groups except for the youngest one. Selfishness concerns remain by and large stable over all age groups, and they are almost always significant. ${ }^{7}$

In order to assess the robustness of our results so far we estimate the effects of age and gender also with a different approach. We produce, to start with, a single, pooled estimation of equation (4). Then, using the estimated parameters $\hat{\varepsilon}_{k}$ and $\hat{p}_{k}$, we compute the probability by which each single subject is assigned to a specific social preference type, conditional on the observed pattern of choices. We calculate equation (3) for each individual and type. This yields the probabilities to observe a given pattern of choices conditional on a type, i.e., $P\left(x_{i} \mid k_{i}\right)$, where - with a slight abuse of notation $-x_{i}$ denotes the choices and $k_{i}=1, \ldots 5$ denotes the type of individual $i$. Finally, using Bayes rule we can compute the probability that an individual $i$ is of type $k_{i}$, given the observed choices, i.e., $P\left(k_{i}=h \mid x_{i}\right)$, where $h=1, \ldots, 5$. For example, the probability that individual $i$ belongs to the Selfishness-type $\left(k_{i}=1\right)$, given the observed choices $x_{i}$, is:

$$
P_{i}\left(k_{i}=1 \mid x_{i}\right)=\frac{p\left(x_{i} \mid k=1\right) \hat{p}_{1}}{p\left(x_{i} \mid k=1\right) \hat{p}_{1}+p\left(x_{i} \mid k=2\right) \hat{p}_{2}+p\left(x_{i} \mid k=3\right) \hat{p}_{3}+p\left(x_{i} \mid k=4\right) \hat{p}_{4}+p\left(x_{i} \mid k=5\right) \hat{p}_{5}}
$$

In five separate (tobit) regressions we regress subject $i$ 's probability of being classified as a specific type on age, gender and an interaction term between age and gender. Note that we use an ordinal variable for the age group in all regressions - assigning values $0,1,2,3$, or 4 for the five different age groups of 8/9-, 10/11-, 12/13-, 14/15-, and 16/17-year olds. ${ }^{8}$ Table 9 presents the results of this analysis.

\section{Table 9 about here}

\footnotetext{
${ }^{7}$ From the envy games $\mathbf{N x}$ and $\mathbf{N y}$ we can classify a subject as selfish if she chooses "Left" in both games. For these subjects (roughly $40 \%$ of all participants) we can check their types in all other games where pure selfishness is not feasible. Interestingly, we find that a majority of them behaves consistent with the Maximinprediction in most other games. Hence, the second most important concern for selfish players, on average, is welfare maximization if their own payoff is not affected.

${ }^{8}$ The results do not change qualitatively if we use the subjects' exact age.
} 
The probability of Selfishness as a subject's type is constant across the five age groups and is not explained by gender. Efficiency, however, is increasing with age for boys and constant for girls. More precisely, the probability of being of the Efficiency-type is the same for boys and girls in the youngest age group of eight- to nine-year olds, but it is significantly higher for boys in all other age groups. Maximin-preferences become more prominent with increasing age for girls, but their prominence remains constant across all age groups for boys. On the contrary, the probability of being of the Maximin-type is significantly higher for girls than for boys in all age groups except for the youngest one.

The likelihood of exhibiting $F \& S$-preferences is decreasing with age, for both boys and girls. There are no significant gender differences in the two youngest age groups up to the age of eleven years. In the three oldest age groups girls have significantly higher values, i.e., they care more about inequality than boys. Finally, the probability that a subject's behavior is explained by the $E R C$-model is decreasing with increasing age for males. However, there are no significant gender differences in the different age groups. The likelihood of exhibiting $E R C$-preferences is lower than for all other social preference types.

The overall picture emerging from Table 9 can be summarized as follows: When children and teenagers grow older, they are less likely to be motivated by inequality aversion, while efficiency-concerns become much more important for boys, and the desire to maximize the payoff of the worst-off group member becomes more widespread among girls.

From data collected in a post-experimental questionnaire we can also examine how socio-demographic variables are related to a subject's social preferences. Including the weekly amount of pocket money, a dummy for sharing the room with siblings, and a dummy for being the only child in the family into the regressions (see Table 10) does not change our general results. However, we find evidence that children who share their rooms with siblings are significantly more likely to be of the Efficiency-type and less likely to hold Maximinpreferences. Moreover, the probability of being of the Maximin-type is significantly lower for subjects who receive more weekly pocket money, and $F \& S$-preferences are more common among these subjects.

Table 10 about here 


\section{Conclusion}

We have studied the influence of age and gender on the distribution of individual social preferences in an experiment where subjects had to make simple, fully incentivized allocation choices. The experiment was run with more than 800 eight- to seventeen-year old children and adolescents. Each participant had to make eight choices, from which we have been able to estimate social preference types for every participating individual. Our model is able to consider five types of preferences: selfishness, efficiency concerns (by maximizing the sum of payoffs), maximin preferences (by maximizing the payoff of the worst off), and two forms of inequality aversion (based on the models by Fehr and Schmidt, 1999, and Bolton and Ockenfels, 2000).

Our results show that roughly $20 \%$ of decision makers in our experiment behave selfishly, and this fraction does neither depend on age nor on gender. Pure inequality aversion plays a role for a non-negligible fraction of decision maker in our younger age groups (explaining about 30\% of decisions for our group of eight- and nine-year olds), where the Fehr and Schmidt (1999) model turns out to be the empirically more suitable model to explain choices than ERC (Bolton and Ockenfels, 2000). In general, pure inequality aversion becomes less important as our subjects grow older. While the decline is somewhat less steep for girls than for boys, the age effect is clearly visible for both, dropping to around 5\% of subjects estimated to have inequality aversion preferences in the group of sixteen- to seventeen-year olds. However, one has to bear in mind that both inequality aversion models abstract from efficiency concerns. Consequently, it is not too surprising that, once efficiency clearly comes into play by the design of the allocation decisions, pure inequality aversion models do not fare very well in predicting choice behavior.

Other types of social preferences follow a clear pattern with age and gender. While efficiency concerns are increasing with age in our male sample (from about $30 \%$ at the age of eight to roughly $50 \%$ at the age of seventeen) and stay constant around $20 \%$ for females, the pattern is reversed for maximin-preferences. The latter become more important for females when they grow up, but stay rather constant for boys. It has to be emphasized that the youngest children in our sample neither show any significant difference in the importance of efficiency concerns for boys and girls nor in the importance of maximin-preferences. Hence, 
both concerns seem to be equally relevant in young children. However, in the teenage years a strikingly divergent development of boys and girls takes place.

It is certainly an important route for future research to study why this is the case, and at this stage, it is only possible to speculate about the potential driving forces behind the divergence between females' and males' social preferences when they grow older. One conceivable mechanism is social learning. For instance, there is evidence that the impact of role models on the behavior of teens becomes strongly differentiated for men and women in adolescence (Kail and Cavanaugh, 2010). How these role models are associated with the evolution of social preferences and why they could make maximin-preferences more prevalent in women and efficiency-concerns more important in men's allocation decisions seems worthwhile investigating in greater detail in the future.

In any case, it appears to be relevant for the understanding of social preferences and their origins to study how they change across childhood and adolescence and at which age gender differences occur. While social preferences might be rather stable in adulthood (even though we have little direct empirical evidence on their stability across different adult age groups, either), they seem to be developing in a systematic way in growing up children. Economists should be interested in the evolution of (social) preferences and possible gender differences in their development because social preferences shape economically relevant decisions of teenagers in the domains of education, employment, and consumption. Our paper should be seen as a first step in providing large-scale experimental evidence on the relationship of social preferences with age and gender. Much more has to be done. For instance, we even lack a comprehensive treatment of gender differences in social preferences among adult decision makers. ${ }^{9}$ In an excellent overview Croson and Gneezy (2009) look at gender differences in preferences. No study in their overview provides a comprehensive treatment of the distribution across females and males over the five preference types that we discussed in this paper. Especially efficiency concerns and maximin-preferences have not been studied systematically in papers on gender differences, as far as we know. Hence, some of the apparent inconclusiveness of the results of studies on gender differences in adults could be due to the neglect of these two motives. While single studies provide important evidence

\footnotetext{
${ }^{9}$ Unfortunately, neither Engelmann and Strobel (2004) nor Charness and Rabin (2002) split up their results with regard to gender. In a comment on the former paper using a subset of their games Fehr, Naef and Schmidt (2006) find a weakly significant effect of women being more egalitarian than men.
} 
on a possible interaction of gender and social preferences, we want to make a case here for more comprehensive and larger-scale experiments under controlled conditions as a promising way to advance research in this area.

Economists should, furthermore, care about the development of social preferences in childhood because the results of economic experiments might prove helpful in optimizing (economic) education for children. For instance, it could give guidance on how to make children aware of different sharing norms when they interact. Given our results, it is very likely that older girls and boys prefer different solutions in certain allocation problems, and being knowledgeable of the differences could avoid conflicts in negotiations or bargaining in private life in families and with friends, and in professional life in companies and organizations. 


\section{References}

Almås, Ingvild, Alexander W. Cappelen, Erik Ø. Sørensen, and Bertil Tungodden. 2010. "Fairness and the Development of Inequality Acceptance.” Science 328 (28 May): 11761178.

Benenson, Joyce F., Joanna Pascoe, and Nicola Radmore. 2007. “Children's Altruistic Behavior in the Dictator Game.” Evolution and Human Behavior 28(3): 168-175.

Bolton, Gary E., and Axel Ockenfels. 2000. “ERC: A Theory of Equity, Reciprocity, and Competition.” American Economic Review 90(1): 166-193.

Camerer, Colin F. 2003. Behavioral Game Theory. Princeton: Princeton University Press.

Charness, Gary, and Martin Dufwenberg. 2006. "Promises and Partnership." Econometrica 74(6): 1579-1601.

Charness, Gary, and Matthew Rabin. 2002. "Understanding Social Preferences with Simple Tests.” Quarterly Journal of Economics 117(3): 817-869.

Costa-Gomes, Miguel, Vincent P. Crawford, and Bruno Broseta. 2001. "Cognition and Behavior in Normal-Form Games: An Experimental Study.” Econometrica 69(5): 11931235.

Croson, Rachel, and Uri Gneezy. 2009. “Gender Differences in Preferences.” Journal of Economic Literature 47(2): 448-474.

Dauphin, Anyck, Abdel-Rahmen El Lahga, Bernard Fortin, and Guy Lacroix. 2010. “Are Children Decision-Makers Within the Household?” Economic Journal, forthcoming.

Engelmann, Dirk, and Martin Strobel. 2004. "Inequality Aversion, Efficiency, and Maximin Preferences in Simple Distribution Experiments.” American Economic Review 94(4): 857-869.

Fehr, Ernst, Georg Kirchsteiger, and Arno Riedl. 1993. "Does Fairness Prevent Market Clearing? An Experimental Investigation.” Quarterly Journal of Economics 108(2): 437459.

Fehr, Ernst, and Klaus M. Schmidt. 1999. “A Theory of Fairness, Competition, and Cooperation.” Quarterly Journal of Economics 114(3): 817-868.

Fehr, Ernst, and Simon Gächter. 2000. „Fairness and Retaliation: The Economics of Reciprocity.” Journal of Economic Perspectives 14(3): 159-181. 
Fehr, Ernst, Michael Naef, and Klaus Schmidt. 2006. "Inequality Aversion, Efficiency, and Maximin Preferences in Simple Distribution Experiments: Comment.” American Economic Review 96(5): 1912-1917.

Fehr, Ernst, Helen Bernhard, and Bettina Rockenbach. 2008. "Egalitarianism in Young Children.” Nature 454(28 August): 1079-1084.

Gummerum, Michaela, Yaniv Hanoch, Monika Keller, Katie Parsons, and Alegra Hummel. 2010. "Preschoolers" Allocations in the Dictator Game: The Role of Moral Emotions.” Journal of Economic Psychology 31(1): 25-34.

Harbaugh, William T. 1998. "The Prestige Motive for Making Charitable Transfers.” American Economic Review, Papers and Proceedings 88(2): 277-282.

Harbaugh, William T., Kate Krause, and Steven G. Liday, Jr. 2003. "Bargaining by Children.” Working Paper, University of Oregon.

Kail, Robert V., and John C. Cavanaugh. 2010. Human Development: A Life-Span View. $5^{\text {th }}$ Edition. Belmont, CA: Wadsworth Publishing.

McNeal, James U. 1992. “The Littlest Shoppers.” American Demographics 14(2): 48-52.

Sutter, Matthias, Martin G. Kocher, Daniela Rützler, and Stefan T. Trautmann. 2010. “Delay and Uncertainty in Childhood and Youth - Experiments and their Relation to Real-World Behavior.” University of Innsbruck, Working Paper.

Sutter, Matthias, and Daniela Rützler. 2010. “Gender Differences in Competition Emerge Early in Life.” University of Innsbruck, Working Papers in Economics and Statistics 2010-14.

Vesterlund, Lise. 2003. “The Informational Value of Sequential Fundraising.” Journal of Public Economics 87(3-4): 627-657. 


\section{Tables and Figures}

Table 1: Taxation games (payoffs in euro)

\begin{tabular}{llll|lll}
\hline \hline & \multicolumn{3}{c}{ Game Fx } & \multicolumn{3}{c}{ Game Ex } \\
& Left & Middle & Right & Left & Middle & Right \\
\hline Person 1 payoff & 6.8 & 7.2 & 7.6 & 8.4 & 6.8 & 5.2 \\
Person 2 payoff & 4 & 4 & 4 & 4.8 & 4.8 & 4.8 \\
$\begin{array}{l}\text { Person 3 payoff } \\
\text { Total payoff }\end{array}$ & 3.6 & 2 & 0.4 & 1.2 & 1.6 & 2 \\
\hline $\begin{array}{l}\text { Prediction } \\
\text { Selfish }\end{array}$ & 14.4 & 13.2 & 12 & 14.4 & 13.2 & 12 \\
$\begin{array}{l}\text { Efficiency } \\
\text { Maximin }\end{array}$ & Left & Middle & Right & Left & Middle & Right \\
F\&S & Left & & & Left & & Right \\
ERC & Left & & & & & Right \\
\hline \hline
\end{tabular}

Table 2: Envy games (payoffs in euro)

\begin{tabular}{|c|c|c|c|c|c|c|c|c|c|}
\hline & \multicolumn{3}{|c|}{ Game N } & \multicolumn{3}{|c|}{ Game Nx } & \multicolumn{3}{|c|}{ Game Ny } \\
\hline & Left & Middle & Right & Left & Middle & Right & Left & Middle & Right \\
\hline Person 1 payoff & 6.4 & 5.2 & 4.0 & 6.4 & 5.2 & 4.0 & 4.0 & 5.2 & 6.4 \\
\hline Person 2 payoff & 3.2 & 3.2 & 3.2 & 3.6 & 3.2 & 2.8 & 3.6 & 3.2 & 2.8 \\
\hline Person 3 payoff & 2.0 & 1.2 & 0.4 & 2.0 & 1.2 & 0.4 & 0.4 & 1.2 & 2.0 \\
\hline Total payoff & 11.6 & 9.6 & 7.6 & 12.0 & 9.6 & 7.2 & 8.0 & 9.6 & 11.2 \\
\hline \multicolumn{10}{|l|}{ Prediction } \\
\hline Selfish & Left & Middle & Right & Left & & & Left & & \\
\hline Efficiency & Left & & & Left & & & & & Right \\
\hline Maximin & Left & & & Left & & & & & Right \\
\hline F\&S & & & Right & Left & & Right & Left & & \\
\hline ERC & & Middle & & Left & Middle & & Left & Middle & \\
\hline
\end{tabular}

Table 3: "Rich and Poor” games (payoffs in euro)

\begin{tabular}{|c|c|c|c|c|c|c|c|c|c|}
\hline & \multicolumn{3}{|c|}{ Game R } & \multicolumn{3}{|c|}{ Game P } & \multicolumn{3}{|c|}{ Game Ey } \\
\hline & Left & Middle & Right & Left & Middle & Right & Left & Middle & Right \\
\hline Person 1 payoff & 2.0 & 3.2 & 4.4 & 3.2 & 4.4 & 5.6 & 5.2 & 6.8 & 8.4 \\
\hline Person 2 payoff & 4.8 & 4.8 & 4.8 & 1.6 & 1.6 & 1.6 & 3.6 & 3.6 & 3.6 \\
\hline Person 3 payoff & 1.6 & 1.2 & 0.8 & 2.8 & 2.4 & 2.0 & 2.0 & 1.6 & 1.2 \\
\hline Total payoff & 8.4 & 9.2 & 10.0 & 7.6 & 8.4 & 9.2 & 10.8 & 12.0 & 13.2 \\
\hline \multicolumn{10}{|l|}{ Prediction } \\
\hline Selfish & Left & Middle & Right & Left & Middle & Right & Left & Middle & Right \\
\hline Efficiency & & & Right & & & Right & & & Right \\
\hline Maximin & Left & & & Left & Middle & Right & Left & & \\
\hline $\mathrm{F} \& S$ & & & Right & Left & & & Left & & \\
\hline ERC & & & Right & Left & & & Left & & \\
\hline
\end{tabular}


Table 4: Number of participants by age and gender

\begin{tabular}{llllllll} 
& \multicolumn{3}{c}{} & \multicolumn{3}{c}{ All subjects } & \multicolumn{3}{c}{ Subjects with correct answers in } \\
& Girls & Boys & Total & Girls & Boys & Total & $\%$ valid \\
\hline & 56 & 60 & $\mathbf{1 1 6}$ & 31 & 33 & $\mathbf{6 4}$ & $55.2 \%$ \\
\hline 8/9 years $\left(3^{\text {rd }}\right.$ grade) & 144 & 95 & $\mathbf{2 3 9}$ & 101 & 65 & $\mathbf{1 6 6}$ & $69.5 \%$ \\
$10 / 11$ years $\left(5^{\text {th }}\right.$ grade) & 122 & 88 & $\mathbf{2 1 0}$ & 96 & 74 & $\mathbf{1 7 0}$ & $81.0 \%$ \\
$12 / 13$ years $\left(7^{\text {th }}\right.$ grade $)$ & 106 & 63 & $\mathbf{1 6 9}$ & 92 & 54 & $\mathbf{1 4 6}$ & $86.4 \%$ \\
$14 / 15$ years $\left(9^{\text {th }}\right.$ grade $)$ & 86 & 63 & $\mathbf{1 4 9}$ & 77 & 56 & $\mathbf{1 3 3}$ & $89.3 \%$ \\
$16 / 17$ years $\left(11^{\text {th }}\right.$ grade $)$ & 514 & 369 & $\mathbf{8 8 3}$ & 397 & 282 & $\mathbf{6 7 9}$ & $76.9 \%$ \\
\hline Total & &
\end{tabular}

Table 5: Taxation games - Choice frequencies

\begin{tabular}{lccc|ccc} 
& \multicolumn{3}{c}{ Game Fx } & \multicolumn{3}{c}{ Game Ex } \\
& Left & Middle & Right & Left & Middle & Right \\
\hline Person 1 payoff & 6.8 & 7.2 & 7.6 & 8.4 & 6.8 & 5.2 \\
Person 2 payoff & 4.0 & 4.0 & 4.0 & 4.8 & 4.8 & 4.8 \\
Person 3 payoff & 3.6 & 2.0 & 0.4 & 1.2 & 1.6 & 2.0 \\
\hline Choices, percentages & & & & & & \\
Total sample & 69.4 & 18.7 & 11.9 & 32.3 & 9.8 & 57.9 \\
Boys & 64.5 & 19.2 & 16.3 & 43.7 & 9.7 & 46.6 \\
Girls & 72.8 & 18.4 & 8.8 & 24.3 & 9.9 & 65.8 \\
8/9 years old & 59.4 & 15.6 & 25.0 & 38.1 & 12.7 & 49.2 \\
10/11 years old & 60.2 & 22.9 & 16.9 & 30.5 & 9.2 & 60.4 \\
12/13 years old & 67.1 & 22.9 & 10.0 & 27.2 & 10.1 & 62.7 \\
14/15 years old & 72.6 & 17.8 & 9.6 & 39.3 & 6.2 & 54.5 \\
16/17 years old & 85.0 & 10.5 & 4.5 & 30.8 & 12.8 & 56.4 \\
Engelmann and Strobel (2004) & 86.7 & 6.7 & 6.7 & 40.0 & 16.7 & 43.3 \\
\hline \hline
\end{tabular}

Table 6: Envy games - Choice frequencies

\begin{tabular}{lccc|ccc|ccc}
\hline & \multicolumn{3}{c}{ Treatment N } & \multicolumn{3}{c}{ Treatment Nx } & \multicolumn{3}{c}{ Treatment Ny } \\
& Left & Middle & Right & Left & Middle & Right & Left & Middle & Right \\
\hline Person 1 payoff & 6.4 & 5.2 & 4.0 & 6.4 & 5.2 & 4.0 & 4.0 & 5.2 & 6.4 \\
Person 2 payoff & 3.2 & 3.2 & 3.2 & 3.6 & 3.2 & 2.8 & 3.6 & 3.2 & 2.8 \\
Person 3 payoff & 2.0 & 1.2 & 0.4 & 2.0 & 1.2 & 0.4 & 0.4 & 1.2 & 2.0 \\
\hline Choices, percentage & & & & & & & & & \\
Total sample & 69.6 & 12.1 & 18.3 & 89.1 & 7.0 & 4.0 & 44.8 & 17.4 & 37.8 \\
Boys & 71.9 & 11.4 & 16.7 & 89.3 & 6.1 & 4.6 & 45.4 & 13.1 & 41.5 \\
Girls & 68.0 & 12.6 & 19.4 & 88.9 & 7.6 & 3.5 & 44.4 & 20.5 & 35.1 \\
8/9 years old & 46.0 & 22.2 & 31.8 & 65.1 & 19.1 & 15.9 & 46.9 & 12.5 & 40.6 \\
10/11 years old & 67.5 & 12.1 & 20.5 & 86.6 & 8.5 & 4.9 & 45.5 & 6.7 & 47.9 \\
12/13 years old & 70.6 & 8.8 & 20.6 & 92.9 & 2.9 & 4.1 & 44.1 & 15.3 & 40.6 \\
14/15 years old & 76.7 & 12.3 & 11.0 & 90.4 & 8.2 & 1.4 & 37.0 & 24.7 & 38.4 \\
16/17 years old & 74.4 & 11.3 & 14.3 & 97.0 & 3.0 & 0.0 & 52.6 & 27.8 & 19.6 \\
Engelmann/Strobel (2004) & 70.0 & 26.7 & 3.3 & 76.7 & 13.3 & 10.0 & 60.0 & 16.7 & 23.3 \\
\hline \hline
\end{tabular}


Table 7: Rich and Poor games - Choice frequencies

\begin{tabular}{lccc|ccc|ccc}
\hline & \multicolumn{3}{c}{ Treatment R } & \multicolumn{3}{c}{ Treatment P } & \multicolumn{3}{c}{ Treatment Ey } \\
& Left & Middle & Right & Left & Middle & Right & Left & Middle & Right \\
\hline Person 1 payoff & 2.0 & 3.2 & 4.4 & 3.2 & 4.4 & 5.6 & 5.2 & 6.8 & 8.4 \\
Person 2 payoff & 4.8 & 4.8 & 4.8 & 1.6 & 1.6 & 1.6 & 3.6 & 3.6 & 3.6 \\
Person 3 payoff & 1.6 & 1.2 & 0.8 & 2.8 & 2.4 & 2.0 & 2.0 & 1.6 & 1.2 \\
\hline Choices, percentage & & & & & & & & & \\
Total sample & 47.0 & 27.4 & 25.6 & 39.3 & 21.5 & 39.2 & 50.1 & 14.3 & 35.6 \\
Boys & 38.4 & 29.5 & 32.0 & 33.0 & 18.8 & 48.2 & 42.0 & 11.0 & 47.0 \\
Girls & 53.2 & 25.8 & 21.0 & 43.8 & 23.4 & 32.8 & 55.8 & 16.7 & 27.5 \\
8/9 years old & 46.9 & 21.9 & 31.3 & 32.8 & 20.3 & 46.9 & 46.9 & 15.6 & 37.5 \\
10/11 years old & 49.7 & 17.0 & 33.3 & 44.6 & 19.3 & 36.1 & 55.5 & 18.3 & 26.2 \\
12/13 years old & 50.3 & 21.3 & 28.4 & 43.5 & 23.5 & 32.9 & 50.6 & 14.1 & 35.3 \\
14/15 years old & 38.4 & 43.8 & 17.8 & 31.5 & 21.2 & 47.3 & 43.2 & 11.6 & 45.2 \\
16/17 years old & 49.2 & 32.6 & 18.2 & 39.1 & 22.6 & 38.4 & 51.9 & 12.0 & 36.1 \\
Engelmann/Strobel (2004) & 53.3 & 20.0 & 26.7 & 33.3 & 6.7 & 60.0 & 36.7 & 23.3 & 40 \\
\hline \hline
\end{tabular}

Table 8: Estimated distribution of social preference-types by gender and age

\begin{tabular}{|c|c|c|c|c|c|}
\hline & \multirow[b]{2}{*}{ Type } & \multicolumn{2}{|c|}{ Females } & \multicolumn{2}{|c|}{ Males } \\
\hline & & Coefficient & Standard Error & Coefficient & Standard Error \\
\hline \multirow{5}{*}{ Age group 8/9 } & Selfishness & 0.135 & 0.084 & 0.292 *** & 0.112 \\
\hline & Efficiency & $0.219^{* *}$ & 0.090 & $0.268 * * *$ & 0.080 \\
\hline & Maximin & 0.318 & 0.203 & 0.072 & 0.052 \\
\hline & F\&S & $0.292 *$ & 0.158 & 0.338 *** & 0.114 \\
\hline & ERC & 0.036 & 0.035 & 0.031 & 0.030 \\
\hline \multirow[t]{5}{*}{ Age group 10/11 } & Selfishness & $0.186^{* * *}$ & 0.052 & $0.138 * *$ & 0.058 \\
\hline & Efficiency & $0.249 * * *$ & 0.051 & $0.350 * * *$ & 0.072 \\
\hline & Maximin & 0.356 *** & 0.062 & $0.270 * * *$ & 0.082 \\
\hline & $F \& S$ & 0.166 *** & 0.049 & $0.168 * *$ & 0.068 \\
\hline & ERC & 0.043 & 0.029 & 0.074 & 0.054 \\
\hline \multirow[t]{5}{*}{ Age group 12/13 } & Selfishness & $0.138 * *$ & 0.064 & $0.199 * * *$ & 0.064 \\
\hline & Efficiency & 0.180 *** & 0.066 & $0.414 * * *$ & 0.078 \\
\hline & Maximin & 0.468 *** & 0.068 & $0.293 * * *$ & 0.087 \\
\hline & $F \& S$ & $0.191 * * *$ & 0.055 & 0.061 & 0.041 \\
\hline & ERC & 0.023 & 0.027 & 0.033 & 0.036 \\
\hline \multirow[t]{5}{*}{ Age group $14 / 15$} & Selfishness & $0.109 * *$ & 0.054 & 0.053 & 0.078 \\
\hline & Efficiency & $0.334 * * *$ & 0.071 & $0.600 * * *$ & 0.085 \\
\hline & Maximin & $0.475 * * *$ & 0.086 & $0.320 * * *$ & 0.116 \\
\hline & $F \& S$ & 0.065 & 0.043 & 0.000 & 0.000 \\
\hline & ERC & 0.017 & 0.055 & 0.027 & 0.024 \\
\hline \multirow[t]{5}{*}{ Age group 16/17 } & Selfishness & $0.141^{* *}$ & 0.064 & $0.270^{* * *}$ & 0.088 \\
\hline & Efficiency & 0.152 *** & 0.042 & $0.459 * * *$ & 0.080 \\
\hline & Maximin & $0.609 * * *$ & 0.091 & $0.271^{* * *}$ & 0.076 \\
\hline & $F \& S$ & 0.060 & 0.053 & 0.000 & 0.000 \\
\hline & ERC & 0.038 & 0.027 & 0.000 & 0.000 \\
\hline
\end{tabular}

Note: ***, **, * denote significance at the 1\%, 5\%, 10\% level. 
Table 9: Determinants of social-preference types (second step regressions)

\begin{tabular}{|c|c|c|c|c|c|}
\hline Explanatory variables & Selfishness & "Efficiency & Maximin & F\&S & ERC \\
\hline Age & $\begin{array}{l}-0.009 \\
(0.011)\end{array}$ & $\begin{array}{l}0.044 * * \\
(0.018)\end{array}$ & $\begin{array}{c}0.013 \\
(0.017)\end{array}$ & $\begin{array}{l}-0.036 * * * \\
(0.011)\end{array}$ & $\begin{array}{l}-0.013 * * * \\
(0.005)\end{array}$ \\
\hline Female & $\begin{array}{l}-0.008 \\
(0.037)\end{array}$ & $\begin{array}{l}-0.053 \\
(0.059)\end{array}$ & $\begin{array}{c}0.087 \\
(0.057)\end{array}$ & $\begin{array}{l}-0.002 \\
(0.036)\end{array}$ & $\begin{array}{l}-0.024 \\
(0.017)\end{array}$ \\
\hline Age*Female & $\begin{array}{c}0.002 \\
(0.015)\end{array}$ & $\begin{array}{l}-0.057 * * \\
(0.023)\end{array}$ & $\begin{array}{c}0.026 \\
(0.023)\end{array}$ & $\begin{array}{c}0.018 \\
(0.015)\end{array}$ & $\begin{array}{l}0.011 * \\
(0.007)\end{array}$ \\
\hline Constant & $\begin{array}{l}0.161 \text { *** } \\
(0.028)\end{array}$ & $\begin{array}{l}0.319 * * * \\
(0.044)\end{array}$ & $\begin{array}{l}0.272 \text { *** } \\
(0.042)\end{array}$ & $\begin{array}{l}0.179 * * * \\
(0.027)\end{array}$ & $\begin{array}{l}0.068 * * * \\
(0.012)\end{array}$ \\
\hline \# of observations & 679 & 679 & 679 & 679 & 679 \\
\hline Age+Age*Female & $\begin{array}{l}-0.006 \\
(0.010)\end{array}$ & $\begin{array}{l}-0.013 \\
(0.016)\end{array}$ & $\begin{array}{l}0.039 * * * \\
(0.015)\end{array}$ & $\begin{array}{l}-0.018 * \\
(0.010)\end{array}$ & $\begin{array}{l}-0.002 \\
(0.004)\end{array}$ \\
\hline Female+(Age*Female) & $\begin{array}{l}-0.006 \\
(0.026)\end{array}$ & $\begin{array}{l}-0.109 * * * \\
(0.040)\end{array}$ & $\begin{array}{l}0.112 * * * \\
(0.039)\end{array}$ & $\begin{array}{c}0.015 \\
(0.025)\end{array}$ & $\begin{array}{l}-0.013 \\
(0.011)\end{array}$ \\
\hline Female+(Age*Female)*2 & $\begin{array}{l}-0.003 \\
(0.019)\end{array}$ & $\begin{array}{l}-0.166 * * * \\
(0.030)\end{array}$ & $\begin{array}{l}0.138 \text { *** } \\
(0.029)\end{array}$ & $\begin{array}{l}0.033 * \\
(0.019)\end{array}$ & $\begin{array}{l}-0.002 \\
(0.009)\end{array}$ \\
\hline Female+(Age*Female $) * 3$ & $\begin{array}{l}-0.001 \\
(0.023)\end{array}$ & $\begin{array}{l}-0.223 * * * \\
(0.036)\end{array}$ & $\begin{array}{l}0.164 \text { *** } \\
(0.034)\end{array}$ & $\begin{array}{l}0.051 \text { ** } \\
(0.022)\end{array}$ & $\begin{array}{c}0.010 \\
(0.010)\end{array}$ \\
\hline Female+(Age*Female $) * 4$ & $\begin{array}{c}0.002 \\
(0.033)\end{array}$ & $\begin{array}{l}-0.280 \text { *** } \\
(0.052)\end{array}$ & $\begin{array}{l}0.189 \text { *** } \\
(0.050)\end{array}$ & $\begin{array}{l}0.068 * * \\
(0.033)\end{array}$ & $\begin{array}{c}0.021 \\
(0.015)\end{array}$ \\
\hline
\end{tabular}

Notes: ***, **, * denote significance at the 1\%,5\%, 10\% level, standard errors in parentheses.

a) Age+Age*Female measures the effect of age in female subjects; b) Female+(Age*Female)*x - where $\mathrm{x}=0$, $1, \ldots, 4-$ measures the effect of female in different age groups.

Table 10: Determinants of social-preference types including background variables (second-step regressions)

\begin{tabular}{lccccc}
\hline \hline Explanatory variables & Selfishness & Efficiency & Maximin & F\&S & ERC \\
\hline Age & -0.015 & $0.052 * * *$ & 0.019 & $-0.044 * * *$ & $-0.013 * *$ \\
Female & $(0.012)$ & $(0.019)$ & $(0.018)$ & $(0.012)$ & $(0.005)$ \\
& -0.013 & -0.035 & 0.073 & -0.002 & -0.023 \\
Age*Female & $(0.038)$ & $(0.059)$ & $(0.057)$ & $(0.037)$ & $(0.017)$ \\
& 0.004 & $-0.062 * * *$ & 0.029 & 0.018 & $0.011 *$ \\
Pocket money & $(0.015)$ & $(0.023)$ & $(0.023)$ & $(0.015)$ & $(0.007)$ \\
& 0.001 & 0.000 & $-0.002 * *$ & $0.001 *$ & 0.000 \\
Share room & $(0.001)$ & $(0.001)$ & $(0.001)$ & $(0.001)$ & $(0.000)$ \\
& -0.024 & $0.069 * *$ & $-0.051 *$ & 0.002 & 0.006 \\
Only child & $(0.019)$ & $(0.031)$ & $(0.029)$ & $(0.019)$ & $(0.009)$ \\
& 0.018 & 0.034 & -0.003 & -0.036 & -0.012 \\
Constant & $(0.027)$ & $(0.043)$ & $(0.041)$ & $(0.026)$ & $(0.012)$ \\
& $0.173 * * *$ & $0.276 * * *$ & $0.297 * * *$ & $0.187 * * *$ & $0.068 * * *$ \\
\# of observations & $(0.030)$ & $(0.048)$ & $(0.046)$ & $(0.030)$ & $(0.014)$ \\
\hline \hline
\end{tabular}

Note: $* * *, * *, *$ denote significance at the $1 \%, 5 \%, 10 \%$ level, standard errors in parentheses. 
Figure 1: Girls' estimated distribution of social preference-types
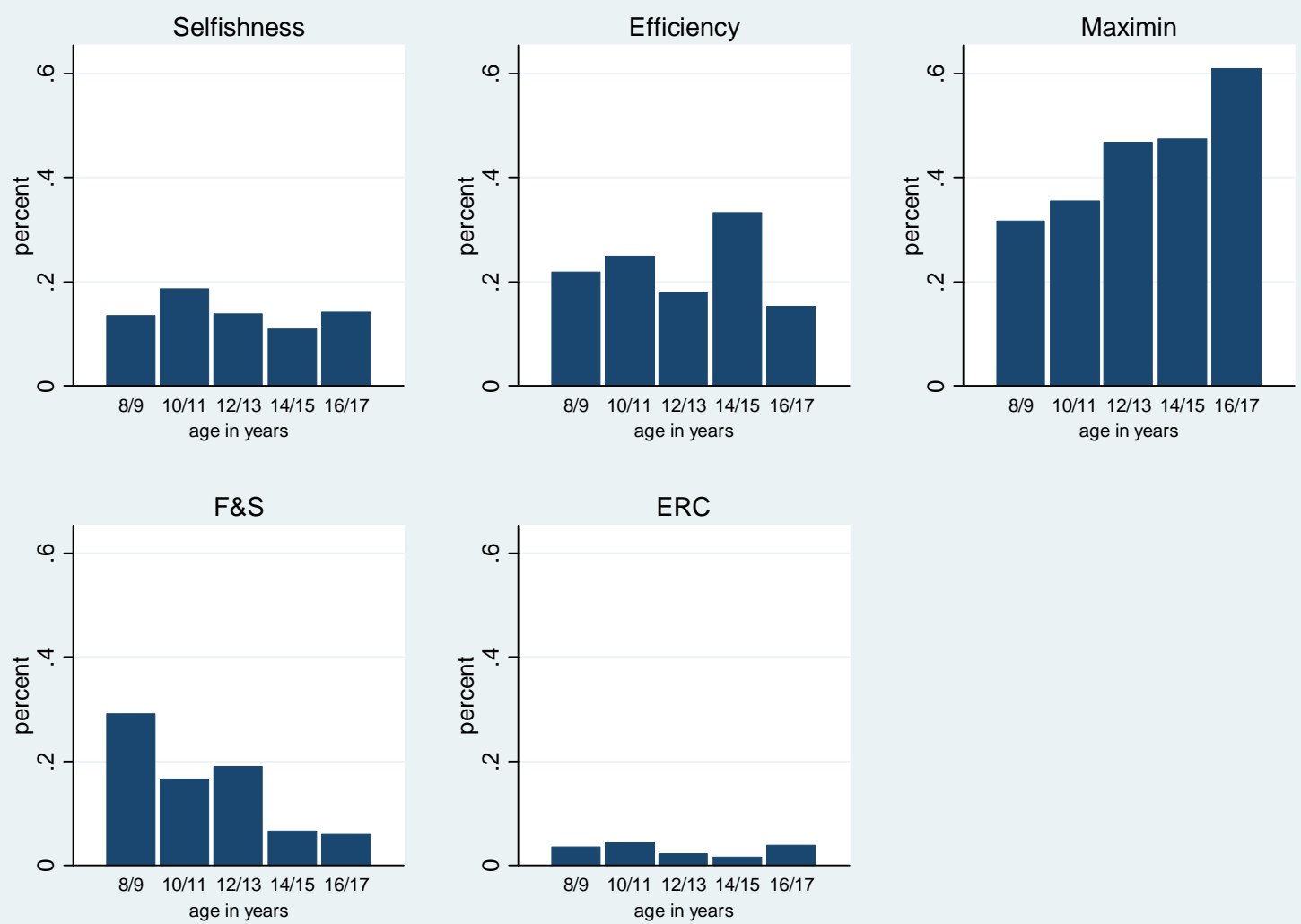
Figure 2: Boys' estimated distribution of social preference-types
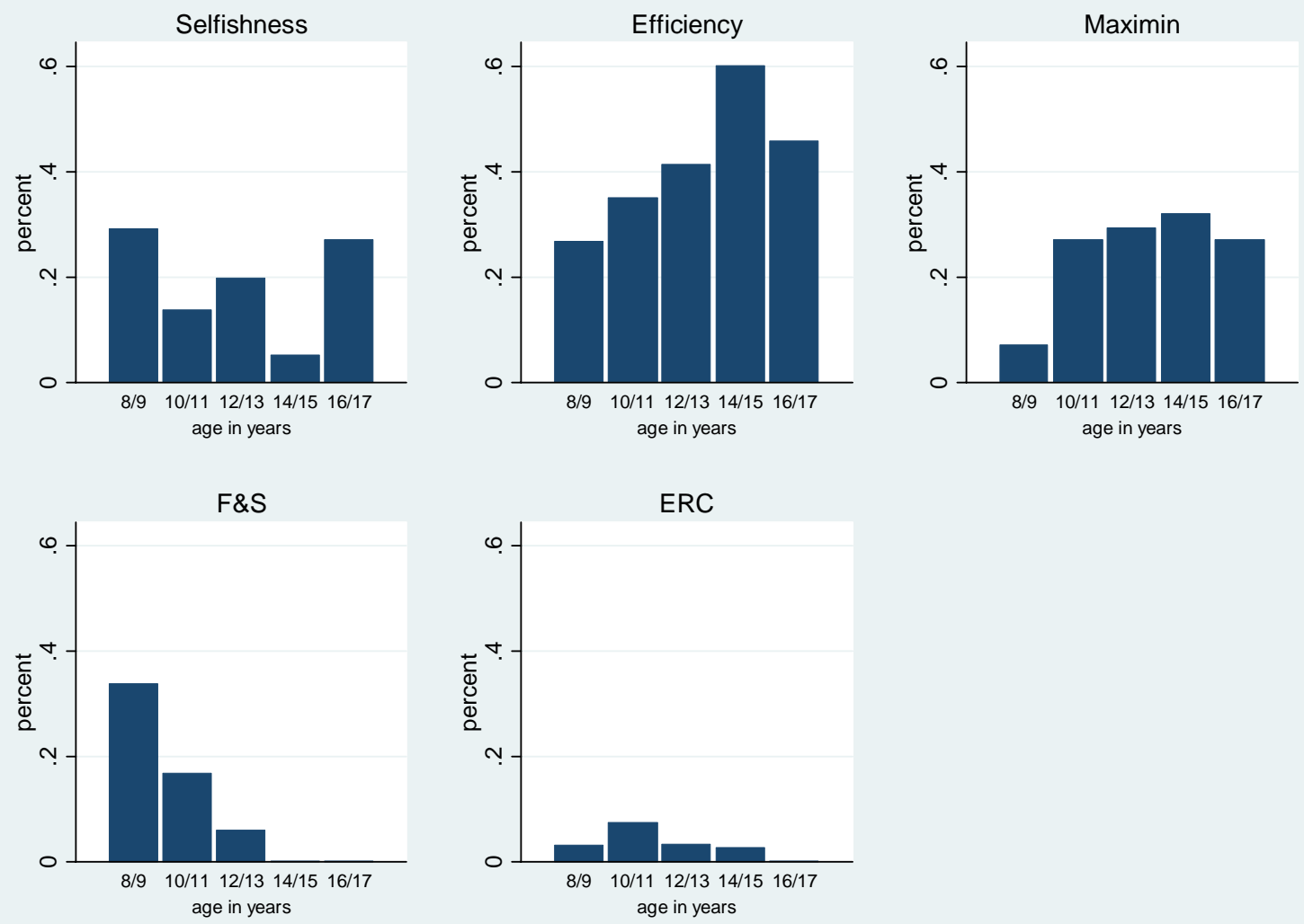


\section{Appendix (not intended for publication)}

\section{Experimental Instructions}

Welcome to our game. Before we start, we will explain the rules of the game to you. From now on, please don't speak to your neighbor and listen carefully. You can earn money in this game. We will give you the money in cash within the next two weeks. We will put your money in a sealed envelope, which is labeled with your id-code. This envelope will be given personally to you by us. It is important that you listen carefully now, so that you understand the rules of our game. If you have any questions, we will answer them after we have explained the rules of the game.

In this game you have to decide how you are going to divide a certain amount of money among three people. We call those three people person 1, person 2, and person 3 . Person 2 decides on the allocation of the money.

At the end of the game each of you will draw a role (person 1, person 2, or person 3) out of this bag. Additionally we will form groups of three people for this game. Each group consists of one student from your class, one student from your parallel class, and one student from another class in the same year, but in a different school. Furthermore each group consists of one person 1, one person 2 and one person 3. In each group person 2 decides on the allocation of the payoffs.

Let's now turn to the allocation of the payoffs. For this purpose we have prepared an example task that looks very similar in structure to what you will see in the actual experiment. In this example - and in all eight games in the experiment - there are three possibilities to divide some money. With option "Left" person 1 gets $2 €$ in this example, person 2 gets $4 €$ and person 3 gets $6 €$. With option "Middle” person 1 gets $1 €$, person 2 gets $4 €$ and person 3 gets $7.8 €$. With option “Right” person 1 gets $2.8 €$, person 2 gets $4 €$ and person 3 gets $4.4 €$.

[Slide used on the overhead projector]

$\begin{array}{llll} & & & \\ & & & \\ & & & \\ \text { Person } 1 & 2.00 € & 1.00 € & 2.80 € \\ \text { Person 2 } & 4.00 € & 4.00 € & 4.00 € \\ \text { Person 3 } & 6.00 € & 7.80 € & 4.40 €\end{array}$




\section{Remember, only person 2 decides on the allocation of the payoffs.}

All of you receive a decision sheet with altogether eight such decisions to make. Please decide eight times either for "Left”, "Middle” or "Right”, always in the role of person 2. [Ask students why they should fill out their decision sheet in the role of person 2.]

In the end you will get the payoff from one of these eight games. First you will draw a card that determines which person you are in your group. Then each of you may roll this 8sided dice [Show the dice to students.] once after the decisions sheet has been completed. The number shown on the dice will determine the game that is paid out for real. Note that only if you are person 2 then your own decision will determine your payoff. 


\section{The eight games on the decision sheet}

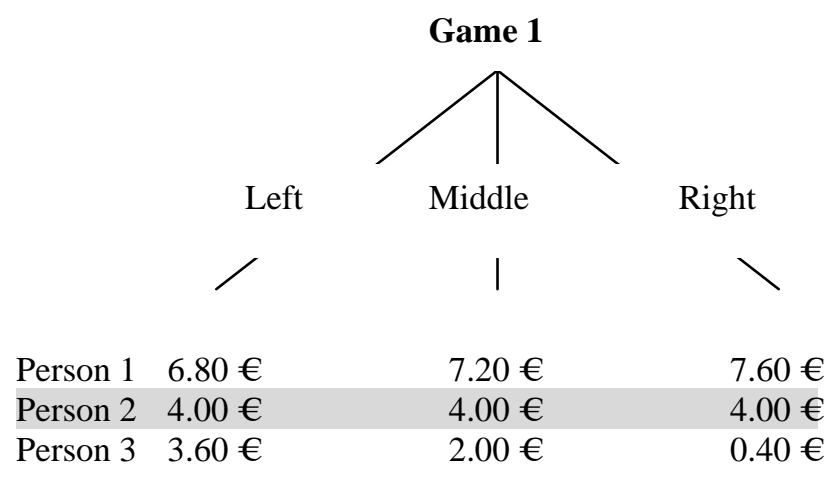

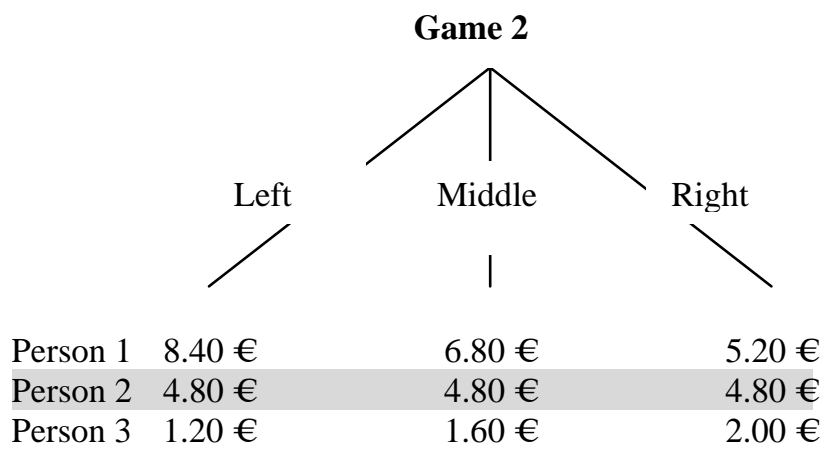

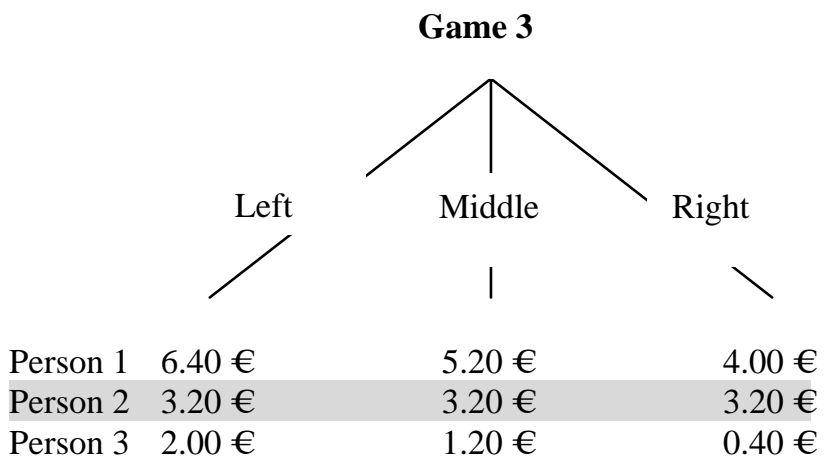

Person $1 \quad 6.40 €$

Person $23.60 €$

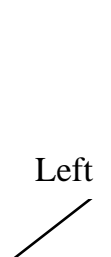

Game 4

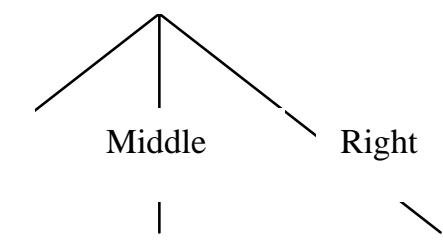

$4.00 €$

$3.20 €$

$2.80 €$

Person $32.00 €$

$1.20 €$

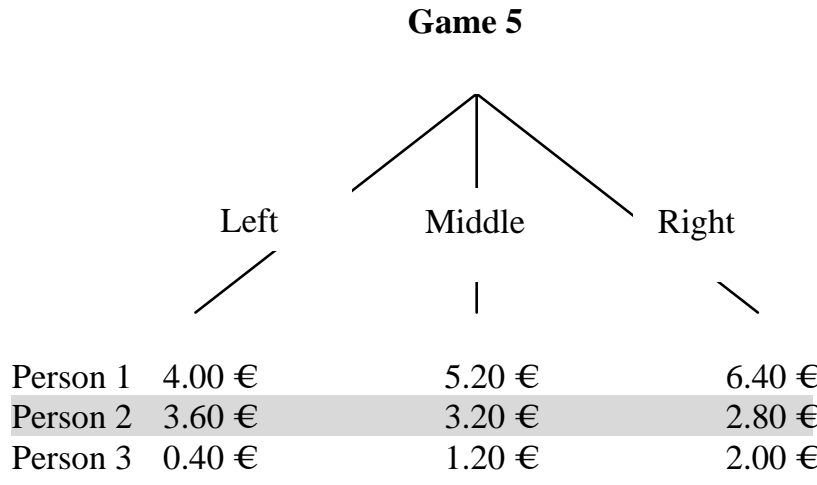

$\begin{array}{llll}\text { Person } 1 & 2.00 € & 3.20 € & 4.40 € \\ \text { Person 2 } & 4.80 € & 4.80 € & 4.80 € \\ \text { Person 3 } & 1.60 € & 1.20 € & 0.80 €\end{array}$

Game 6

$\begin{array}{llll} & & & \\ \text { Person } 1 & 2.00 € & 3.20 € & 4.40 € \\ \text { Person 2 } & 4.80 € & 4.80 € & 4.80 € \\ \text { Person 3 } & 1.60 € & 1.20 € & 0.80 €\end{array}$

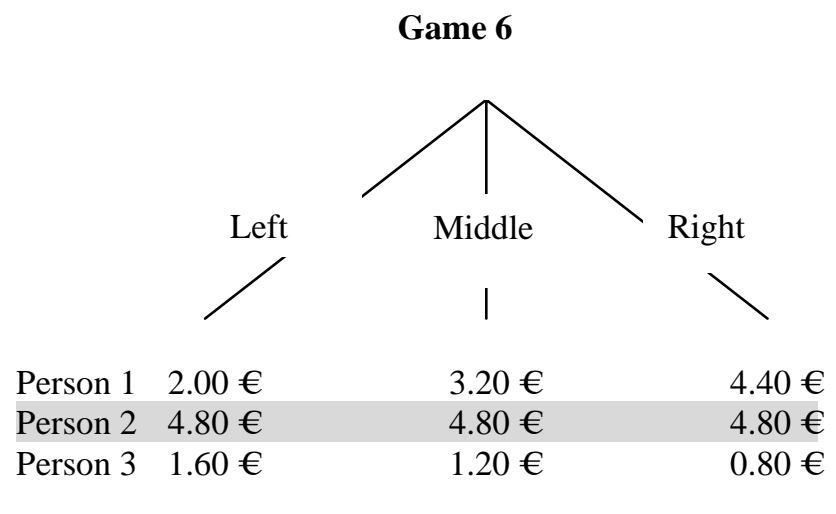

Game 8

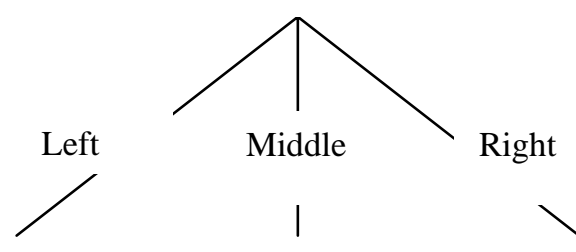

Person $13.20 €$

Person $21.60 €$

$4.40 €$

$1.60 €$

$5.60 €$

$1.60 €$

$2.00 €$
Person $15.20 €$

Person $23.60 €$

Person $32.00 €$

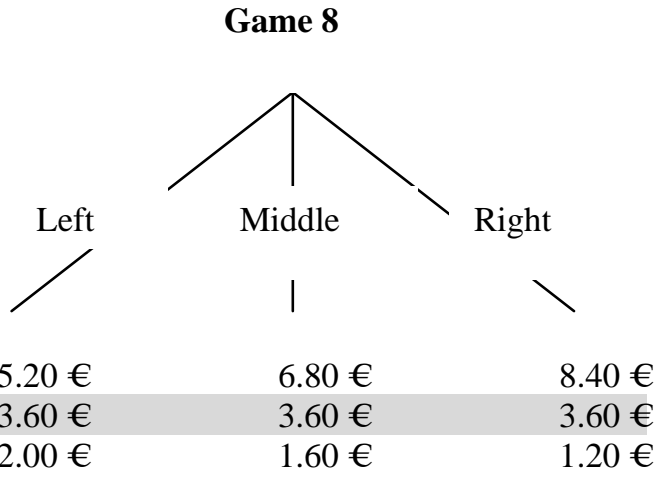

